\title{
Apples and oranges: Understanding what our trainees need
}

\author{
Ara A. Vaporciyan, MD
}

For quite a number of years, there has been a steady debate regarding the divergence of cardiac surgery and general thoracic surgery. ${ }^{1,2}$ Despite this recognition, the United States has maintained the marriage of the 2 disciplines as a single profession. Although most of us would agree that differences do exist, tangible data on the specific differences are partial at best. Ingram and colleagues $^{3}$ have addressed that gap in our understanding with their work in this issue of the Journal, "Practice Patterns of Academic General Thoracic and Adult Cardiac Surgeons." Their findings elucidate quantifiable variations in obvious areas of difference, such as in the common procedures performed, less obvious variations, such as in relative value unit (RVU) generation, and some subtle differences, such as in the type of care that dominates the treatment that each discipline provides. Differences in just what procedures are performed and in the RVUs generated, as Ingram and colleagues ${ }^{3}$ have concluded, certainly carry ramifications for how general thoracic surgeons and cardiac surgeons should optimize the structures of their practices. Like Ingram and colleagues, ${ }^{3}$ I have no intent to use these data to justify either separating our disciplines or maintaining the status quo. Rather, I was intrigued by the educational ramifications of their work.

The obvious differences in the procedures performed by each discipline were not surprising. More noteworthy, however, were the differences in the classes of procedures being performed. For cardiac surgeons, all 10 of the most frequently billed procedures can be classified as providing treatment. On the other hand, for general thoracic surgeons the vast majority of procedures can be classified as diagnostic or evaluative (staging). It is clear that a significant fraction of a general thoracic surgeon's time is spent in diagnosis and evaluation or in preoperative or postoperative clinical decision making, rather than dominantly focused on treatment. This suggestion is substantiated by the data on the top RVU generators for the 2 disciplines. For cardiac surgeons, all of the top $10 \mathrm{RVU}$ generators are treatment related. For thoracic

\footnotetext{
From the Deputy Chair, Department of Thoracic and Cardiovascular Surgery, the Director of Clinical Education and Training, and Professor of Surgery, University of Texas M. D. Anderson Cancer Center, Houston, Tex.

Disclosures: Author has nothing to disclose with regard to commercial support. Received for publication Aug 25, 2014; accepted for publication Aug 25, 2014. Address for reprints: Ara A. Vaporciyan, MD, Department of Thoracic and Cardiovascular Surgery, MD Anderson Cancer Center, 1400 Pressler, Rm 19.6008, Houston, TX 77030 (E-mail: avaporci@mdanderson.org). J Thorac Cardiovasc Surg 2014;148:1167-8 $0022-5223 / \$ 36.00$

Copyright (C) 2014 by The American Association for Thoracic Surgery http://dx.doi.org/10.1016/j.jtcvs.2014.08.035
}

surgeons, at least 4 of the 10 procedures are again part of the pretreatment or posttreatment evaluation of the patient.

Although Ingram and colleagues ${ }^{3}$ discuss the impact of this variation in terms of influencing practice patterns, optimizing distribution of clinic space access versus operating room access, and allocating appropriate physician extender support, I view this information through the lens of an educator. I believe that Ingram and colleagues ${ }^{3}$ have provided one of the most basic components of curricular design, the needs assessment. During the development of a curriculum, the needs of the learners must be identified. Anyone who has ever planned a continuing medical education activity knows how difficult it can be to find hard data documenting the needs of the learners. The usual alternative is to use "expert opinion," but these opinions are always affected by personal bias. This work provides insight into just what our trainees must learn to become successful cardiac surgeons and successful general thoracic surgeons. It becomes clear that training cardiac surgeons requires a heavy focus on the performance of surgical treatment. The decision making that must be learned is focused more heavily on intraoperative decisions. In contrast, although the general thoracic surgeon must still have a clear understanding of intraoperative decision making, there must also be an equal (if not greater) focus on preoperative assessment and postoperative management.

One can easily see how this information could be used in structuring a training program. For instance, the general thoracic component of training might require a greater emphasis to be placed on the trainee's presence in the clinic or on rotations with endoscopists and interventionists. For the cardiac component of training, a greater focus might need to be placed on intraoperative management and skills training. Simulation activities could also be more focused on the basis of these needs; for example, by providing more procedural simulation for cardiac training and more clinical decision-making simulation (board style sessions) for general thoracic training. This information should also affect how we assess our trainees. Case logs, a seemingly indispensable tool for assessing our trainees, may have greater relevance in cardiac training. Alternatively, general thoracic surgeons may require a greater emphasis on tools that evaluate preoperative and postoperative decision making.

From Ingram and colleague's work, ${ }^{3}$ it is clear that each discipline has differing needs with regard to what should be taught and assessed. A similar effort to analyze 
the practice patterns of private practice cardiothoracic surgeons would be equally welcome. Better understanding of what we do as professionals will help us to build efficient and valid educational programs. Considering the time and cost associated with education, every effort to allocate these resources wisely will benefit our profession.

\section{References}

1. Akins CW. The ethical dilemma of thoracic surgery recertification. J Thorac Cardiovasc Surg. 2012;143:521-2. Erratum in: J Thorac Cardiovasc Surg. $2012 ; 143: 1235$.

2. Vaporciyan AA. Who will determine the educational needs of our trainees? J Thorac Cardiovasc Surg. 2012;144:532-3.

3. Ingram MT Jr, Wisner DH, Cooke DT. Practice patterns of academic general thoracic and adult cardiac surgeons. J Thorac Cardiovasc Surg. 2014;148: 1162-6. 